\title{
HUBUNGAN PERSONAL HYGIENE DENGAN MASALAH KEPUTIHAN PADA IBU PEMULUNG DI TPA TADUKAN RAGA STM HILIR
}

\author{
Astriana Fransiska Butarbutar, Juli Fransiska Tumanggor \\ Institut Deli Husada Deli Tua \\ Jl. Besar No. 77 Deli Serdang - Sumatera Utara 20355 \\ Fakultas Kesehatan Masyarakat \\ Email: butarbutarsiska@gmail.com \\ DOI : https://doi.org/10.35451/jkg.v2i2.396
}

\begin{abstract}
Whitish (flour albus) is a condition of the vagina when removing fluid or mucus that resembles pus. Leucorrhoea is not always a disease because there is also normal vaginal discharge. Poor personal hygiene cause vaginal discharge. The purpose of this study was to determine the relationship between personal hygiene and vaginal discharge problems in scavenger mothers in the Landfills Tadukan Raga STM Hilir 2018. The type of research used was descriptive research with a cross sectional approach, namely an analytical survey. The sample of this study amounted to 23 respondents using total sampling. The data analysis was carried out by univariate and bivariate with Chi Square statistic test with a significance limit (a) of 0,05. The reseach showed that the majority of scavenger mothers had good skin hygiene, and good hand and nail hygiene as many as 13 people with a percentage (56,5\%), and having poor Genetalia Hygiene as many as 13 people with a percentage (56,5\%). The conclusion there is no relationship between skin hygiene and vaginal discharge ( $\rho=0,341)$, there is no relationship between hand and nail hygiene with vaginal discharge $(\rho=0,660)$, and there is a correlation between genetalia hygiene and vaginal discharge in scavenger mothers $(\rho=0,019)$. Skin hygiene, hand and nail hygiene are not entirely a factor causing vaginal discharge problems, there are still many other causal factors which are the limitations of this study, while genetalia hygiene greatly affects the occurrence of vaginal discharge problems.
\end{abstract}

Keywords: whitish, Personal hygiene, scavenger mothers 


\section{PENDAhUluan}

Menurut studi Badan Kesehatan Dunia (World Health Organization) Jumlah wanita didunia pada tahun 2013 sebanyak 6,7 milyar jiwa dan yang pernah mengalami keputihan sekitar $75 \%$, sedangkan wanita Eropa pada tahun 2013 sebanyak 739.004 .470 jiwa dan yang mengalami keputihan sebesar $25 \%$. Sekitar $75 \%$ wanita didunia pasti akan mengalami keputihan paling tidak sekali seumur hidup dan sebanyak $45 \%$ wanita mengalami keputihan dua kali atau lebih,sedangkan pada kaum wanita yang berada dieropa angka keputihan sebesar 25\%, dimana 40-50 $\%$ akan mengalami kekambuhan.(Dagasou, dkk. 2014).

$\mathrm{Di}$ Indonesia sekitar $90 \%$ wanita berpotensi mengalami keputihan karena negara Indonesia adalah daerah yang beriklim tropis, sehingga jamur mudah tumbuh dan berkembang yang mengakibatkan banyaknya kasus keputihan pada perempuan Indonesia.(Nurul, dkk. 2011).

Kebersihan lingkungan dan jasmani sangat menentukan derajat kesehatan masyarakat. Salah satu organ tubuh yang penting serta sensitif dan memerlukan perawatan khusus adalah alat reproduksi. Pengetahuan dan perawatan yang baik merupakan faktor penentu dalam memelihara kesehatan reproduksi. Apabila alat reproduksi tidak dijaga kebersihannya maka akan menyebabkan infeksi, yang pada akhirnya dapat menimbulkan penyakit. Dampak yang bisa diakibatkan oleh personal hygiene alat reproduksi yang buruk antara lain, keputihan, vulvitis, vaginitis, vulvovaginitis dan kanker servik. Lingkungan yang tidak bersih dan kebiasaan pemeliharaan personal hygiene yang rendah Pemulung wanita memiliki kerentanan yang besar dalam kesehatan reproduksi sebagai akibat dari lingkungan kerja, tempat tinggal dan kebiasaan pemeliharaan personal hygiene yang rendah.(Wardani, 2012). Berdasarkan penelitian tentang hubungan personal hyegene dengan keputihan pada wanita usia subur di wilayah kerja Puskesmas lingkar Timur dengan hasil penelitian menunjukkan dari 29 wanita usia subur terdapat 22 orang $(75,9 \%)$ wanita usia subur personal hygiene tidak baik mengalami keputihan sedangkan dari 56 wanita usia subur terdapat 30 orang $(53,4 \%)$ wanita usia subur dengan personal hygiene yang baik tidak mengalami keputihan.(Nurhardini, 2012).

Berdasarkan survey awal yang dilakukan di TPA Tadukan raga STM Hilir, bahwa beberapa ibu bekerja sebagai pengumpul barang-barang bekas dan beberapa ibu yang membantu suaminya, dari hasil wawancara yang dilakukan oleh peneliti pada beberapa ibu kurang memperhatikan kebersihan organ genitalia.serta riwayat keputihan apakah pernah mengalami keputihan didapatkan bahwa 8 dari 10 ibu pernah mengalami keputihan.setelah ditanya tentang personal hygiene, 4 orang $(40 \%)$ menjaga personal hygiene dan 6 orang $(60 \%)$ kurang menjaga personal hygiene dengan baik.

\section{METODE}

Penelitian ini merupakan jenis Penelitian deskriptif dengan pendekatan cross sectional untuk mengetahui hubungan personal hygiene dengan masalah keputihan pada ibu pemulung di TPA Tadukan Raga STM Hilir tahun 2018. Populasi penelitian ini adalah seluruh ibu pemulung yang ada di TPA Tadukan Raga STM Hilir. Sampel penelitian sejumlah 23 orang menggunakan teknik total sampling. Seperangkat kuesioner dirancang dan dibagikan kepada responden yang memuat tentang personal hygiene dan check list wawancara untuk mengumpulkan informasi tentang bagaimana para pemulung wanita melakukan personal hygiene. Data selanjutnya ditampilkan dalam bentuk tabel frekuensi. Selanjutnya data dianalisa secara deskriptif untuk menggambarkan 
personal hygiene ibu pemulung di TPA Tadukan raga STM Hilir.

3 HASIL

1. Karakteristik Responden

a. Karakteristik responden berdasarkan umur ibu pemulung

Tabel 1. Distribusi Frekuensi Umur Responden di TPA Tadukan Raga STM Hilir Tahun 2018.

\begin{tabular}{|c|c|c|}
\hline $\begin{array}{c}\text { Umur } \\
\text { Ibu }\end{array}$ & $\mathbf{F}$ & (\%) \\
\hline $30-35$ & 7 & 30,4 \\
\hline Thn & 10 & 43,5 \\
\hline $36-40$ & 6 & 26,1 \\
\hline \multicolumn{3}{|l|}{ Thn } \\
\hline \multicolumn{3}{|l|}{$>40$} \\
\hline \multicolumn{3}{|l|}{ Thn } \\
\hline Total & 23 & 100,0 \\
\hline
\end{tabular}

Frekuensi Mayoritas Umur responden adalah Berumur 36-40 Thn yaitu sebanyak 10 orang dengan persentase ( 43,5 \% ), dan minoritas Umur responden adalah Berumur $>40$ Thn yaitu sebanyak 6 orang dengan persentase ( $26,1 \%$ ).

b. Karakteristik Responden Berdasarkan Agama Ibu pemulung

Tabel 2. Distribusi Frekuensi Agama Responden di TPA Tadukan Raga STM Hilir Tahun 2018.

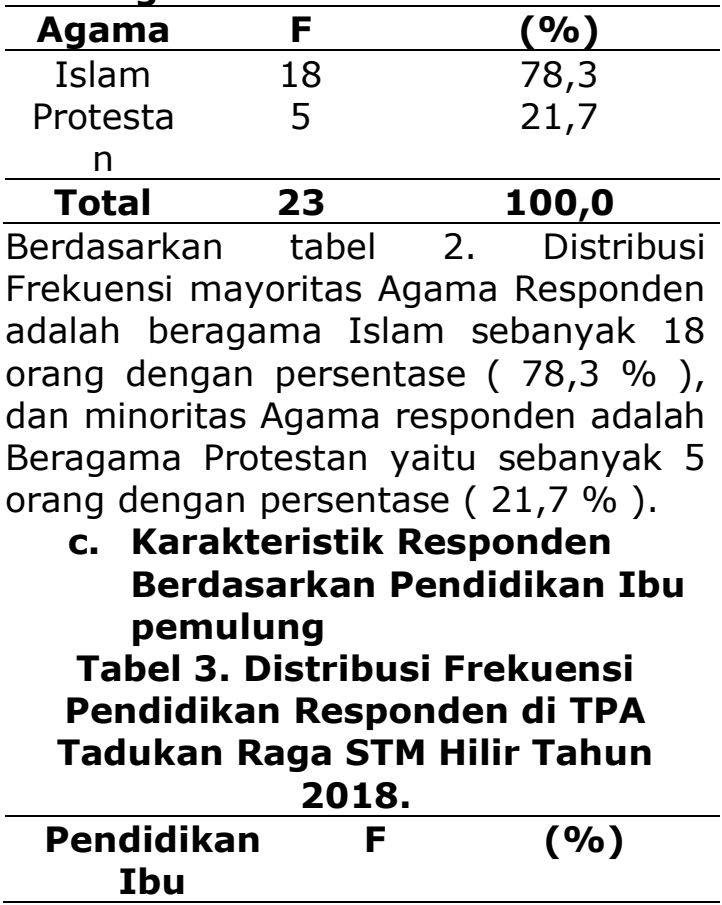

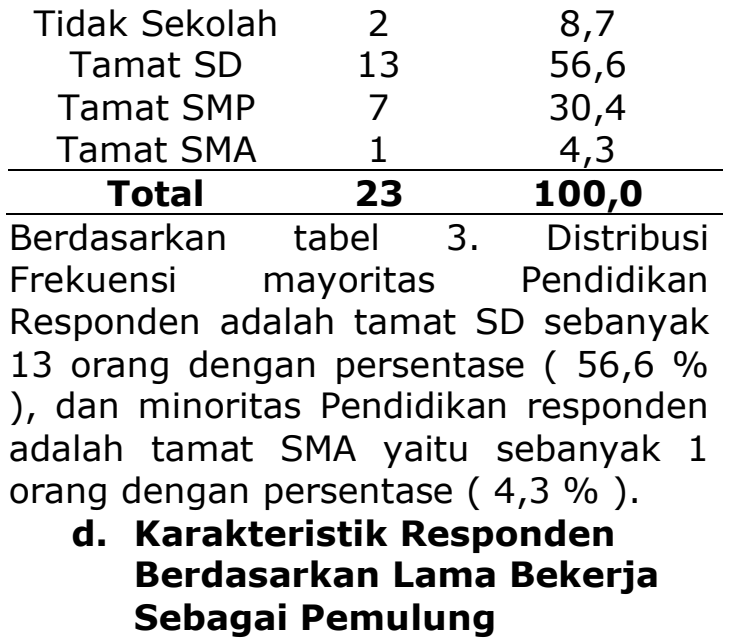

Tabel 4. Distribusi Frekuensi Lama Bekerja Responden di TPA Tadukan Raga STM Hilir Tahun 2018. Lama F (\%) Bekerja

5-15 Thn

16-20 Thn 30,4

17,4

21-26 Thn $5 \quad 21,7$

27-31 Thn $6 \quad 26,2$

\begin{tabular}{ccc}
$>31$ Thn & 1 & 4,3 \\
\hline Total & $\mathbf{2 3}$ & $\mathbf{1 0 0 , 0}$
\end{tabular}

Berdasarkan tabel 4. Distribusi Frekuensi mayoritas Lama bekerja Responden adalah 5-15 Thn sebanyak 7 orang dengan persentase ( 30,4\%), dan minoritas Lama bekerja Responden adalah > 31 Thn yaitu sebanyak 6 orang dengan persentase $(4,3 \%)$.

e. Karakteristik Responden Berdasarkan Waktu Bekerja Ibu Pemulung

Tabel 5. Distribusi Frekuensi Waktu Bekerja Responden di TPA Tadukan Raga STM Hilir Tahun 2018. Waktu F (\%) Bekerja

$\begin{array}{lll}<8 \text { Jam } & 7 & 30,4\end{array}$

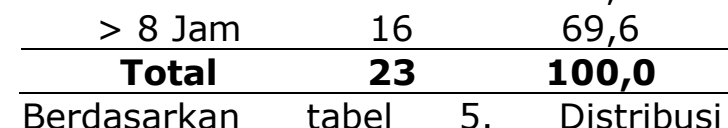
Frekuensi mayoritas Waktu bekerja Responden adalah $>8$ jam sebanyak 16 orang dengan persentase ( $69,6 \%$ ), dan minoritas Lama bekerja Responden adalah > 4 jam yaitu sebanyak 7 orang dengan persentase ( $30,4 \%$ ).

\section{Analisis Univariat Personal Hygiene}


a. Kebersihan Kulit Ibu Pemulung

Tabel 6. Distribusi Frekuensi Kebersihan Kulit Ibu Pemulung di TPA Tadukan Raga STM Hilir Tahun 2018.

\begin{tabular}{ccc}
\hline $\begin{array}{c}\text { Kebersihan } \\
\text { Kulit }\end{array}$ & F & $\mathbf{( \% )}$ \\
\hline BAIK & 13 & 56,5 \\
BURUK & 10 & 43,5 \\
\hline Total & $\mathbf{2 3}$ & $\mathbf{1 0 0 , 0}$ \\
\hline
\end{tabular}

Berdasarkan tabel 6. Menunjukkan bahwa mayoritas responden yang memiliki Kebersihan kulit yang Baik yaitu sebanyak 13 orang dengan persentase $(56,5 \%)$, dan minoritas responden yang memiliki Kebersihan kulit yang Buruk yaitu sebanyak 10 orang dengan persentase ( 43,5\%).

b. Kebersihan Tangan dan Kuku Ibu Pemulung

Tabel 7. Distribusi Frekuensi Kebersihan Tangan dan Kuku Ibu

Pemulung di TPA Tadukan Raga STM Hilir Tahun 2018.

\begin{tabular}{ccc}
\hline $\begin{array}{c}\text { Kebersihan } \\
\text { Tangan dan } \\
\text { Kuku }\end{array}$ & $\mathbf{F}$ & $\mathbf{( \% )}$ \\
\hline BAIK & 13 & 56,5 \\
BURUK & 10 & 43,5 \\
\hline Total & $\mathbf{2 3}$ & $\mathbf{1 0 0 , 0}$ \\
\hline
\end{tabular}

Berdasarkan tabel 7. Menunjukkan bahwa mayoritas responden yang memiliki Kebersihan Tangan dan Kuku yang Baik yaitu sebanyak 13 orang dengan persentase $(56,5 \%)$, dan minoritas responden yang memiliki Kebersihan kulit yang buruk yaitu sebanyak 10 orang dengan persentase ( 43,5\%).

c. Kebersihan Genetalia

Tabel 8. Distribusi Frekuensi Kebersihan Genetalia Ibu

Pemulung di TPA Tadukan Raga STM Hilir Tahun 2018.

\begin{tabular}{ccc}
\hline $\begin{array}{c}\text { Kebersihan } \\
\text { Genetalia }\end{array}$ & F & $\mathbf{( \% )}$ \\
\hline BAIK & 10 & 43,5 \\
BURUK & 13 & 56,5 \\
\hline Total & $\mathbf{2 3}$ & $\mathbf{1 0 0 , 0}$ \\
\hline
\end{tabular}

Berdasarkan tabel 8. Menunjukkan bahwa mayoritas responden yang memiliki Kebersihan Genetalia yang Buruk yaitu sebanyak 13 orang dengan persentase $(56,5 \%)$, dan minoritas responden yang memiliki Kebersihan kulit yang Baik yaitu sebanyak 10 orang dengan persentase (43,5\%).

d. Keputihan Pada Ibu Pemulung

Tabel 9. Distribusi Frekuensi Keputihan Pada Ibu Pemulung di TPA Tadukan Raga STM Hilir Tahun 2018.

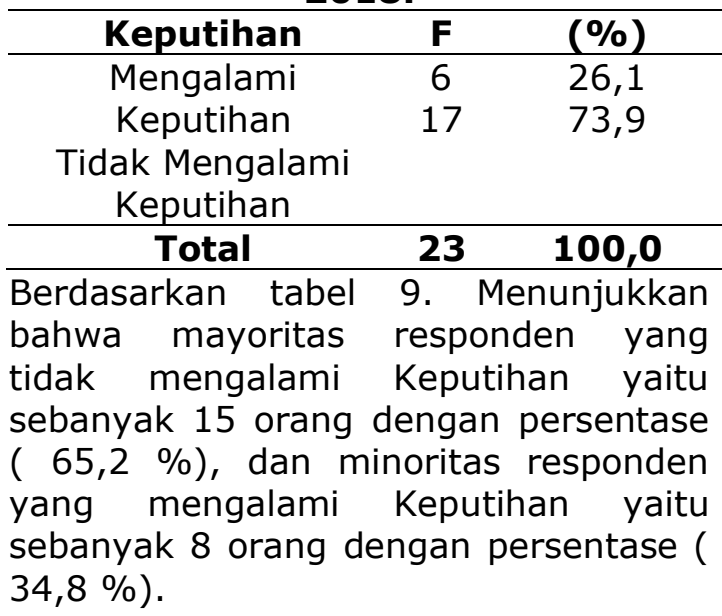

\section{Analisis Bivariat}

a. Kebersihan Kulit Dengan Masalah Keputihan

Tabel 10. Tabel silang Hubungan antara Kebersihan kulit dengan

Masalah Keputihan Pada Ibu Pemulung di TPA Tadukan Raga STM Hilir Tahun 2018.

\begin{tabular}{|c|c|c|c|c|c|c|c|}
\hline & & \multicolumn{4}{|c|}{ Keputihan } & \multicolumn{2}{|c|}{ Total } \\
\hline & & & $\mathrm{Ya}$ & Tidak & $\%$ & $f$ & $\%$ \\
\hline \multirow{2}{*}{$\begin{array}{l}\text { Ke } \\
\text { ber } \\
\text { sihan } \\
\text { Kulit }\end{array}$} & Baik & 2 & $\begin{array}{r}15 \\
, 4 \\
\end{array}$ & 11 & $\begin{array}{r}84 \\
, 6 \\
\end{array}$ & 13 & $\begin{array}{c}100 \\
, 0 \\
\end{array}$ \\
\hline & $\begin{array}{c}\text { Buru } \\
\mathrm{k}\end{array}$ & 4 & $\begin{array}{l}40 \\
, 0\end{array}$ & 6 & $\begin{array}{l}60 \\
, 0\end{array}$ & 10 & $\begin{array}{c}100 \\
, 0\end{array}$ \\
\hline Total & & 6 & $\begin{array}{c}26 \\
, 1\end{array}$ & 17 & $\begin{array}{r}73 \\
, 9\end{array}$ & 23 & $\begin{array}{c}100 \\
, 0\end{array}$ \\
\hline
\end{tabular}

Berdasarkan tabel 10. menunjukkan hasil analisis Tabel Silang antara Kebersihan Kulit dengan Kejadian Keputihan Pada Ibu Pemulung Di TPA Tadukan Raga STM Hilir Tahun 2018 diperoleh bahwa dari 23 Responden Ibu Pemulung menyatakan dengan Mayoritas Ibu yang memiliki Kebersihan Kulit yang Baik dengan Kejadian tidak mengalami keputihan sebanyak 11 Orang( 84,6\%), Minoritas Ibu dengan status Kebersihan Kulit yang Buruk mengalami Keputihan adalah sebanyak 4 orang( $40,0 \%)$. Hasil uji statistik Chi Square diperoleh 
nilai $\mathrm{p}$ value 0,341 atau nilai $\mathrm{a}>0,05$, maka HO diterima dan Ha ditolak, yang dapat disimpulkan bahwa Tidak ada Hubungan yang signifikan antara Kebersihan Kulit Ibu pemulung dengan Kejadian Keputihan Pada Ibu Pemulung Di TPA Tadukan Raga STM Hilir Tahun 2018.

Kuku

$$
\text { b. Kebersihan Tangan dan }
$$

dengan Masalah Keputihan

\section{Tabel 11. Tabel silang Hubungan} antara Kebersihan Tangan dan Kuku dengan Masalah Keputihan Pada Ibu Pemulung di TPA Tadukan Raga STM Hilir Tahun 2018.

\begin{tabular}{lccccccc}
\hline & & \multicolumn{3}{c}{ Keputihan } & & \multicolumn{2}{c}{ Total } \\
\hline & Ya & $\%$ & Tidak & $\%$ & $f$ & $\%$ \\
\hline $\begin{array}{l}\text { Keber } \\
\text { sihan } \\
\text { tanga } \\
\begin{array}{l}\text { n \& } \\
\text { kuku }\end{array}\end{array}$ & Baik & 4 & 30,8 & 9 & $\begin{array}{r}69 \\
2\end{array}$ & $\begin{array}{c}1 \\
3\end{array}$ & $\begin{array}{c}100, \\
0\end{array}$ \\
\cline { 2 - 8 } Total & $\mathrm{k}$ & 2 & 20,0 & 8 & $\begin{array}{c}80 \\
, 0\end{array}$ & $\begin{array}{c}1 \\
0\end{array}$ & $\begin{array}{c}100, \\
0\end{array}$ \\
\hline
\end{tabular}

Berdasarkan tabel 11. menunjukkan hasil analisis Tabel Silang antara Kebersihan Tangan dan Kuku dengan Kejadian Keputihan Pada Ibu Pemulung Di TPA Tadukan Raga STM Hilir Tahun 2018 diperoleh bahwa dari 23 Responden Ibu Pemulung menyatakan dengan Mayoritas Ibu yang memiliki Kebersihan Tangan dan Kuku yang Baik dengan tidak mengalami kejadian keputihan sebanyak 9 Orang( 69,2\%) , Minoritas Ibu dengan status Kebersihan Tangan dan Kuku yang Buruk mengalami Keputihan adalah 2 orang ( 20,0\%). Hasil uji statistik Chi Square diperoleh nilai $\mathrm{p}$ value 0,660 atau nilai a $>0,05$, maka HO diterima dan Ha ditolak, yang dapat disimpulkan bahwa Tidak ada Hubungan yang signifikan antara Kebersihan Tangan dan Kuku Ibu pemulung dengan Kejadian Keputihan Pada Ibu Pemulung Di TPA Tadukan Raga STM Hilir Tahun 2018.

\section{c. Kebersihan Genetalia dengan \\ Masalah Keputihan \\ Tabel 12. Tabel silang Hubungan antara Kebersihan Genetalia dengan Masalah Keputihan Pada}

Ibu Pemulung di TPA Tadukan Raga STM Hilir Tahun 2018.

\begin{tabular}{|c|c|c|c|c|c|c|c|}
\hline & & \multicolumn{4}{|c|}{ Keputihan } & \multicolumn{2}{|c|}{ Total } \\
\hline & & Ya & $\%$ & Tidak & $\%$ & $\mathrm{~F}$ & $\%$ \\
\hline \multirow{2}{*}{$\begin{array}{c}\text { Ke } \\
\text { ber } \\
\text { si } \\
\text { han } \\
\text { Ge } \\
\text { ne } \\
\text { talia }\end{array}$} & BAIK & 0 & 0,0 & 10 & 100,0 & 10 & $\begin{array}{l}100, \\
0\end{array}$ \\
\hline & $\begin{array}{l}\text { BUR } \\
\text { UK }\end{array}$ & 6 & $\begin{array}{c}46 \\
2\end{array}$ & 7 & 58,3 & 13 & $\begin{array}{l}100, \\
0\end{array}$ \\
\hline Total & & 6 & $\begin{array}{c}26, \\
1\end{array}$ & 17 & 73,9 & 23 & $\begin{array}{l}100, \\
0\end{array}$ \\
\hline
\end{tabular}

Berdasarkan tabel 12. menunjukkan hasil analisis antara Kebersihan Genetalia dengan Kejadian Keputihan Pada Ibu Pemulung di TPA Tadukan Raga STM Hilir Tahun 2018 diperoleh bahwa dari 23 Responden Ibu menyatakan dengan Mayoritas yang memiliki Kebersihan Genetalia Buruk dengan Mengalami Keputihan sebanyak 6 Orang ( 46,2 \%), Minoritas Ibu dengan Kebersihan Genetalia Baik mengalami Keputihan ada sebanyak 0 orang ( $0 \%)$. Hasil uji statistik Chi Square diperoleh nilai $\mathrm{p}$ value 0,019 atau nilai a $<0,05$, maka HO ditolak dan $\mathrm{Ha}$ diterima, yang dapat disimpulkan bahwa ada Hubungan yang signifikan antara Kebersihan Genetalia dengan Kejadian Keputihan Pada Ibu Pemulung Di TPA Tadukan Raga STM Hilir 2018.

\section{PEMBAhAsan}

a. Hubungan Kebersihan Kulit Dengan Masalah Keputihan Pada Ibu pemulung

Dari hasil diatas peneliti menyimpulkan bahwa ibu pemulung memiliki personal hygiene yang baik tidak mengalami keputihan, disisi lain banyak teori mengatakan bahwa keputihan terjadi bukan hanya dari personal hygiene yang buruk saja tapi dapat dipengaruhi dari status gizi, berat badan, pola makan yang tidak teratur, stress dan masih banyak lagi. Pada saat peneliti melakukan wawancara dan membagikan kuisioner, peneliti mengamati kebersihan kulit dari ibu pemulung, terlihat bahwa kebersihan kulit ibu memang terlihat kurang bersih, namun setiap ibu pemulung kembali kerumah mereka wajib membersihkan diri mereka 
dengan baik, dapat disimpulkan bahwa mereka sangat memperhatikan kebersihan kulit mereka.

\section{b. Hubungan Kebersihan Tangan Dan Kuku dengan Masalah Keputihan Pada Ibu Pemulung}

Kebersihan tangan, dan kuku yang dimaksud pada penelitian ini adalah kebersihan yang dilakukan pemulung dengan cara mencuci tangan dengan air yang mengalir dan sabun memotong kuku tangan secara teratur. Kebersihan tangan, kuku pada pemulung saat wawancara berdasarkan jawaban responden dapat dilihat bahwa ibu pemulung mencuci tangan dengan sabun sebelum dan sesudah makan, dan kuku mereka tidak selalu dalam keadaan bersih.Berdasarkan penglihatan secara langsung, terlihat bahwa tangan, kuku kurang bersih.Tetapi kuku - kuku mereka tidak panjang. Tangan, dan kuku yang kurang bersih akan mudah kuman penyakit masuk kedalam tubuh kita. Namun pada saat diwanwancarai mereka mengatakan setiap kembali kerumah mereka akan membersihkan kuku dan tangan dengan baik. Karena mereka akan melakukan aktifitas memasak jadi mereka memastikan kebersihan tangan dan kuku mereka harus tetap bersih.

\section{c. Hubungan Kebersihan Genetalia dengan Masalah Keputihan Pada Ibu Pemulung \\ Keputihan \\ merupakan} permasalahan klasik pada kebanyakan wanita. Ironinya kebanyakan wanita tidak megetahui tentang keputihan dan penyebab keputihan. beberapa ibu bekerja sebagai pengumpul barangbarang bekas dan beberapa ibu yang membantu suaminya, dari hasil wawancara yang dilakukan oleh peneliti pada beberapa ibu kurang memperhatikan kebersihan organ genitalia. Kurangnya perhatian terhadap kebersihan genetalia dapat menyebabkan keputihan pada ibu pemulung.

\section{KESIMPULAN}

Tidak ada Hubungan yang signifikan antara Kebersihan Kulit Ibu pemulung dengan Kejadian Keputihan Pada Ibu Pemulung Di TPA Tadukan Raga STM Hilir Tahun 2018, a $=0,05$ dengan nilai $p=0,341$. Tidak Ada hubungan yang signifikan antara Kebersihan Tangan dan Kuku dengan masalah keputihan pada Ibu Pemulung di TPA Tadukan Raga Tahun 2018, a = 0,05 dengan nilai $p=0,660$. Ada hubungan yang signifikan antara Kebersihan Genetalia dengan masalah keputihan pada Ibu Pemulung di TPA Tadukan Raga Tahun 2018 a $=0,05$ dengan nilai $p=0,019$.

\section{DAFTAR PUSTAKA}

Abrori, Dkk. (2017). Faktor yang Berhubungan Dengan Kejadian Keputihan Patologis Siswi SMAN 1 Simpang Hilir Kabupaten Kayong Utara. Fakultas IImu Kesehatan, Universitas Muhammadiyah Pontianak.

Bahari, hamid.(2018). Cara Mudah Atasi Keputihan. Yogyakarta: Buku Biru.

Dagasou, Sarjte Ellen. (2014). Gambaran Tingkat Pengetahuan Ibu Tentang Keputihan di Poliklinik Obstetri/Ginekologi RSU Pancaran Kasih GMIM Manado. Universitas Sam Ratulangi.

Khuzaiyah, Siti, Dkk.(2015). Karakteristik Wanita Dengan Flour Albus. STIKES Muhammadiyah Pakajangan Pekalongan.

Melati, Rika.(2012). Hubungan Antara Pengetahuan dan Keterampilan Vulva Hygiene Dengan Kejadian Keputihan pada Ibu Rumah Tangga (Studi didesa Sawah Joho Warungasem Batang).Universitas Kesehatan Semarang.

Notoadmojo, S. (2013). Metodologi Penelitian Kesehatan. Jakarta: Rhineka Cipta

Sastroasmoro,S, Ismail,S. (2014). Dasar-dasar Metodologi Penelitian Klinis. Jakarta: Seto Agung. 
Saraswati, Sylvia. (2015). 52 Penyakit Perempuan. Yogyakarta: kata hati.

Sari,Wening, Dkk. (2012). Panduan Lengkap Kesehatan Wanita. Jakarta: Penebar Plus.

St. Hartina. (2018). Hubungan Tingkat Pengetahuan Remaja Putri Tentang Keputihan dengan Perilaku Personal Hygiene di Madrasah Aliyah Mu'Allimat. Universitas Aisyiyah Yogyakarta.

Utami. (2013). Hubungan Tingkat Pengetahuan Dengan Perilaku Deteksi Dini Kanker Serviks Pada Pasangan Usia Subur Di Wilayah Kerja Puskesmas Sangkrah Kcamatan Pasar Kliwon Surakarta. Surakarta.

Wardani. Novita Eka. (2012). Gambaran Pengetahuan dan Perilaku Personal Hygiene Alat Reproduksi Pada Pemulung Wanita di Pemukiman Pemulung Kelurahan Dewono

Surabaya. Poltekes Kemenkes Surabaya. 